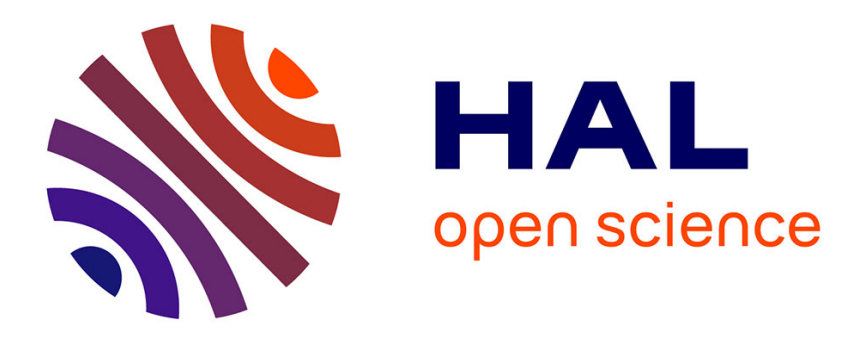

\title{
Note à propos de l'article "Stabilité au vent des hêtraies...".
}

\author{
Maurice Bonneau
}

\section{To cite this version:}

Maurice Bonneau. Note à propos de l'article "Stabilité au vent des hêtraies...". 2005, pp.463. 10.4267/2042/5067 . hal-03449426

\section{HAL Id: hal-03449426 \\ https://hal.science/hal-03449426}

Submitted on 25 Nov 2021

HAL is a multi-disciplinary open access archive for the deposit and dissemination of scientific research documents, whether they are published or not. The documents may come from teaching and research institutions in France or abroad, or from public or private research centers.
L'archive ouverte pluridisciplinaire HAL, est destinée au dépôt et à la diffusion de documents scientifiques de niveau recherche, publiés ou non, émanant des établissements d'enseignement et de recherche français ou étrangers, des laboratoires publics ou privés. 


\section{LIBRE EKPRESSION}

\section{NOTE À PROPOS DE L'ARTICLE "STABILITÉ AU VENT deS hÊtRAiES...”*}

Dans cet article, les auteurs concluent que, pour diminuer les risques de destruction par les tempêtes, il faut parvenir plus vite au diamètre d'exploitabilité, en 90-100 ans au lieu de 120140 ans, avec des arbres courts et à houppier large.

Dans les sols riches, la sylviculture peut suffire à atteindre cet objectif. En sol pauvre, c'est certainement plus difficile. Mais la fertilisation des peuplements adultes peut venir en aide à la sylviculture. Elle doit probablement se situer, au cours de la révolution, à l'issue de la phase de compression, car, appliquée pendant cette phase, elle risque d'augmenter la hauteur, ce qui est contraire à l'objectif proposé.

Après cette phase de décompression, des analyses de sol ou foliaires permettraient de déterminer la formule de fertilisation (ou d'amendement) efficace, à appliquer à intervalles réguliers, tous les 5 ou 10 ans, jusqu'à la fin de la révolution.

On doit se souvenir que la qualité technologique du bois de Hêtre est d'autant meilleure que les accroissements sont plus larges. Une fertilisation des hêtraies adultes ne nuirait donc pas, au contraire, à la qualité des produits.

Des expérimentations dans ce sens sont souhaitables dans des hêtraies à sol acide, peu fertile (Basses-Vosges, Morvan, Montagne Noire, Piémont pyrénéen par exemple).

\footnotetext{
* L'article de V. Badeau, J. Bock, P. Duplat, J.-L. Dupouey, J.-P. Renaud, I. Vinkler "Stabilité au vent des hêtraies : les enseignements de la tempête de 1999" est paru dans la Revue forestière française n 2-2005 "L'avenir du Hêtre dans la forêt française", pp. 143158.
} 